MilitaryTechnicalCollege

Kobry El-Kobbah, Cairo, Egypt

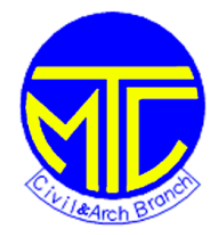

$10^{\text {th }}$ International Conference on Civil and Architecture Engineering

ICCAE-10-2014

\title{
Pollution treatment in water stream bodies using rice husk
}

By

ElNadi,M.H. ${ }^{1}$, ElAzizy, E.M. ${ }^{2}$, Samy, Gh.M. ${ }^{3}$, Abdalla, M.A.F. ${ }^{4}$

1. Professor of Sanitary \& Environmental Engineering, Faculty of Engineering, ASU, Cairo, Egypt. mhnweg@yahoo.com

2. Professor of Water Resources Engineering, Faculty of Engineering, ASU, Cairo, Egypt.

3. Associate Professor of Water Resources Engineering, Faculty of Engineering, ASU, Cairo, Egypt.

4. Ph.D Student of Environmental Eng. \& Engineer in Irrigation Department, Qalubyia Governorate.

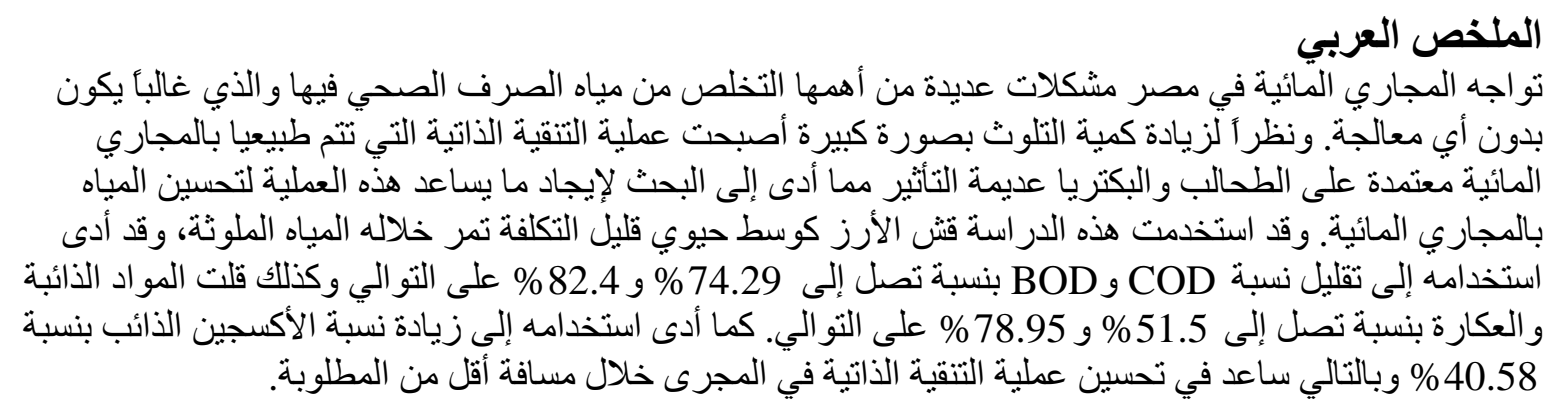

\section{ABSRACT}

Water bodies are facing many problems in Egypt. The most important one is disposing of domestic wastewater mostly without treatment. According to increasing amount of pollution self purification process, which depends mainly on bacteria and algae, become not effective so, it is needed to find what helps this process to improve characteristics of water bodies. This study used rice husk as a low cost bioreactor packing media where polluted water pass through it. It is led to increase dissolved oxygen by percent up to $40.58 \%$, decrease COD and BOD by percents up to $74.29 \% \& 82.4 \%$ respectively. It is also decrease total dissolved solids and turbidity by percents up to $51.5 \%$ \& $78.95 \%$ respectively which helped to improve the self - purification process in water bodies through a less distance than required.

\section{INTRODUCTION}

Water is the necessary resource for life but it faces many problems due to pollution which entered different water bodies mostly without treatment. Wastewater can be defined as the polluted water which is produced from agricultural, domestic or industrial uses. Wastewater treatment is one of the most important considerations in countries because of its harmful effects on human health and environment. Water bodies can assimilate a certain amount of pollution without any serious effects on consequence of self purification due to 
the biological cycle which adjusts itself for greater supply of food or for any other changed conditions [1]. But; with additional disposing of wastewater, it needs more distance to back up the characteristics of water body.

Self purification was exploited for wastewater treatment by algae, such as oxidation ponds, or by aquatic plants, such as wetlands. These types of treatment were done in out of stream using ponds with large areas.

Belment and Centellano [2] studied the degradation of the water quality of the Texcoco River in central Mexico as a result of discharges of raw sewage from communities into the watershed. Constructed wetlands may be appropriate technologies for treating the domestic wastewater generated by small communities in central Mexico. A pilot-scale treatment wetland was constructed to assess the removal of pollutants from wastewater in the small community of Santa María Nativitas in the Rio Texcoco watershed. The system consisting of sedimentation terraces, stabilization pond, subsurface flow wetland (SSFW) and vertical flow wetland (VFW). The removal efficiency was more than $80 \%$ of TSS, COD and nitrate from domestic sewage. Removal of ammonium was less efficient at about $50 \%$.

EI Sergany [3] used sugar cane stalks as a filter media using filtration physical and biological meanings. The test was applied inside three continuous batch reactor columns each one has surface area of $20 \mathrm{~cm}^{2}$. Experiments were made with changing media depth between 8,12 and $20 \mathrm{~cm}$ to know the best removal efficiency of COD, BOD, TSS, N and P from wastewater. The flow rate of wastewater through the filter media was constant (about $1 \mathrm{~L} / \mathrm{h}$ ). The study conclude that the removal efficiencies were max at media depth $=20 \mathrm{~cm}$. The removal efficiency ranged from 70 to $85 \%$ as a maximum value for fine form and from 63 to $67 \%$ as a minimum value for coarse form.

El Nadi, et all [4] used Biomass wastes a media for wastewater treatment. Almond shells were tested for this purpose. Tests by using column scale experiments were done to determine the removal efficiencies of the sewage parameters TSS, COD, BOD, N and P with changing the depth of the media between $(8,12,20 \mathrm{~cm})$ with constant flow rate of wastewater through the media (around $1 \mathrm{~L} / \mathrm{h}$ ). The study results showed that the removal efficiencies were maximum at $\mathrm{h}=20 \mathrm{~cm}$. The study proved that almond shells and sunflower stalks were effective media for wastewater treatment.

In this study, we use agriculture waste inside the water body to improve self purification process which is affected by excess domestic pollution to be done in shorter distance.

Rice husk (figure (1)), which is agriculture waste, was used as a biodegradable media with $50 \mathrm{~cm}$ thickness to improve self purification action inside the water body. 


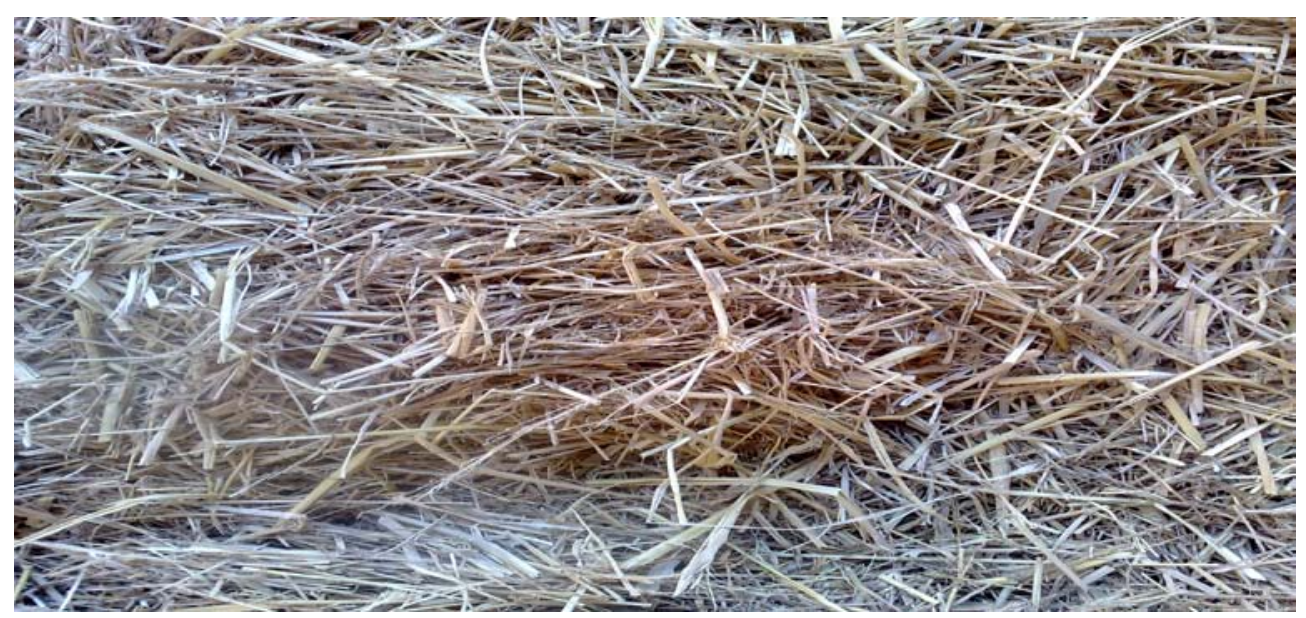

Figure (1) Rice husk

\section{EXPERIMENTAL DESCRIBTION}

The experimental analyses are done at the sanitary engineering laboratory, Faculty of Engineering, Benha University. The experimental work is done on a pilot unit simulate a water stream body. The pilot unit consists of A pilot channel (figure (2)) with dimensions of $30 \mathrm{~cm}$ width, $40 \mathrm{~cm}$ depth and length of $12 \mathrm{~m}$ fed with tap water at the beginning, Sewage Tank disposed wastewater to the pilot presented the source of continues flow wastewater at $25 \mathrm{~cm}$ from the influent point, the water depth in the pilot is $30 \mathrm{~cm}$, The bioreactor packing media of rice husk is installed after $25 \mathrm{~cm}$ from the sewage disposal point and the discharge of water and wastewater pass through it. It is used without any treatment but is cut to size of $2 \mathrm{~cm}$ and work as bio attached growth filter.

Measurements are taken before media, at distances 1, 6 and 11m after media. 


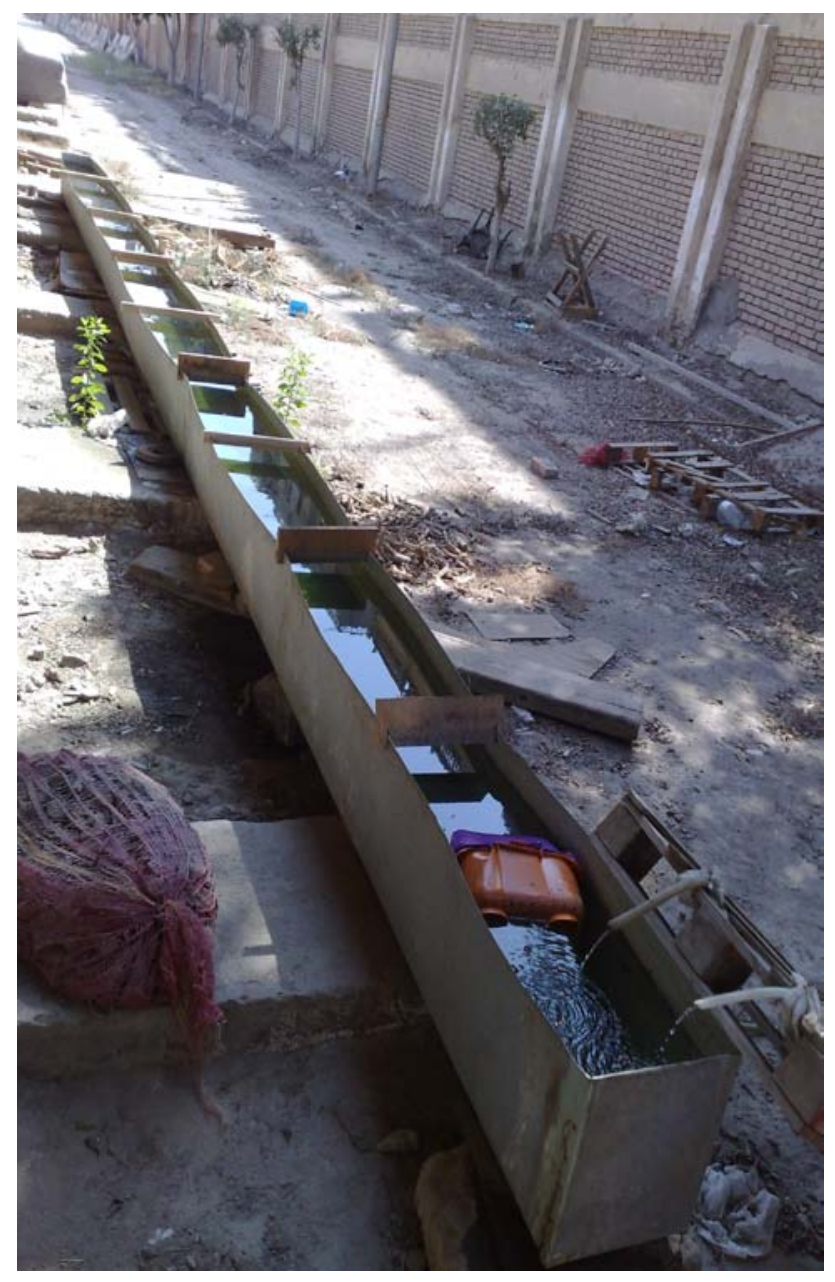

Figure (2) Pilot channel photo

Figure (3) presents the pilot drawing showing the bioreactor location the sampling locations from it during its operation for this study. 


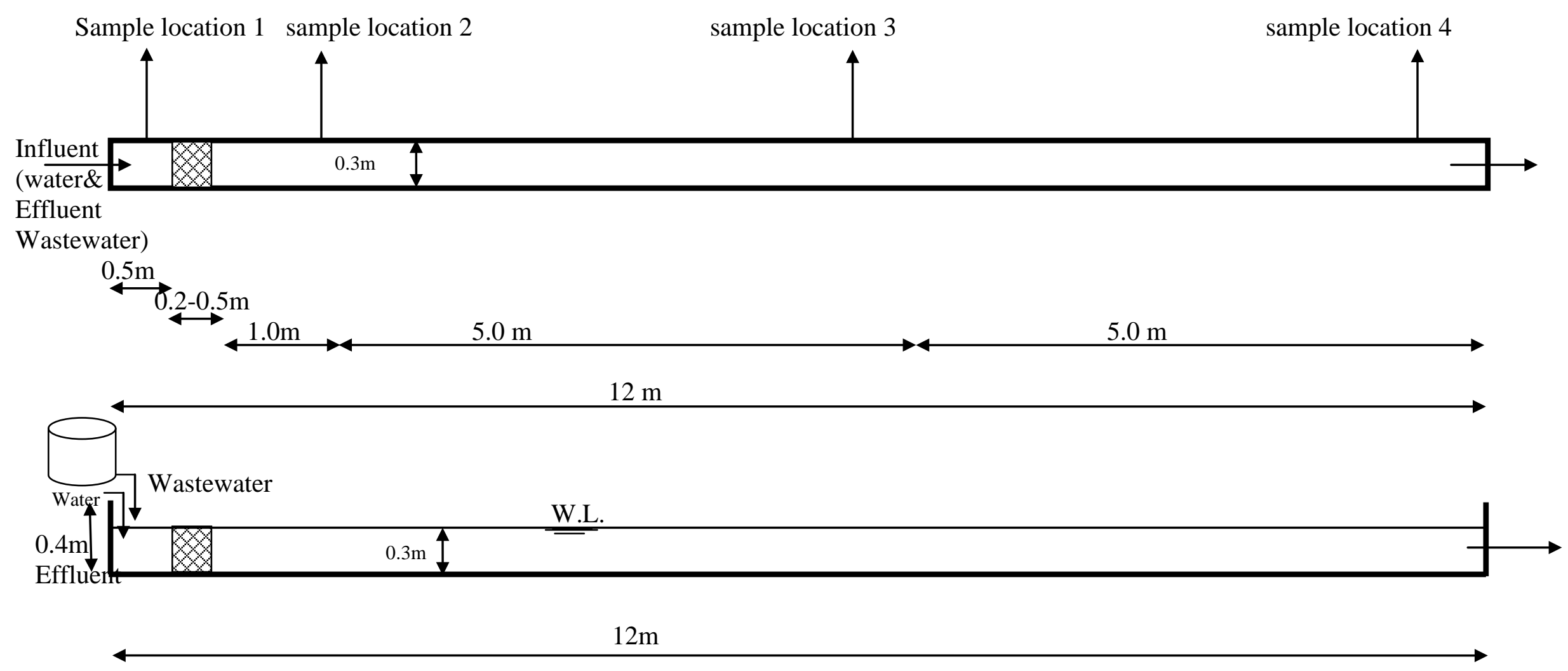

Figure (3) Schematic diagram for pilot 


\section{RESULTS AND DISCUSSION}

Figure (4) represents the dissolved oxygen (DO) concentration through the pilot channel length.

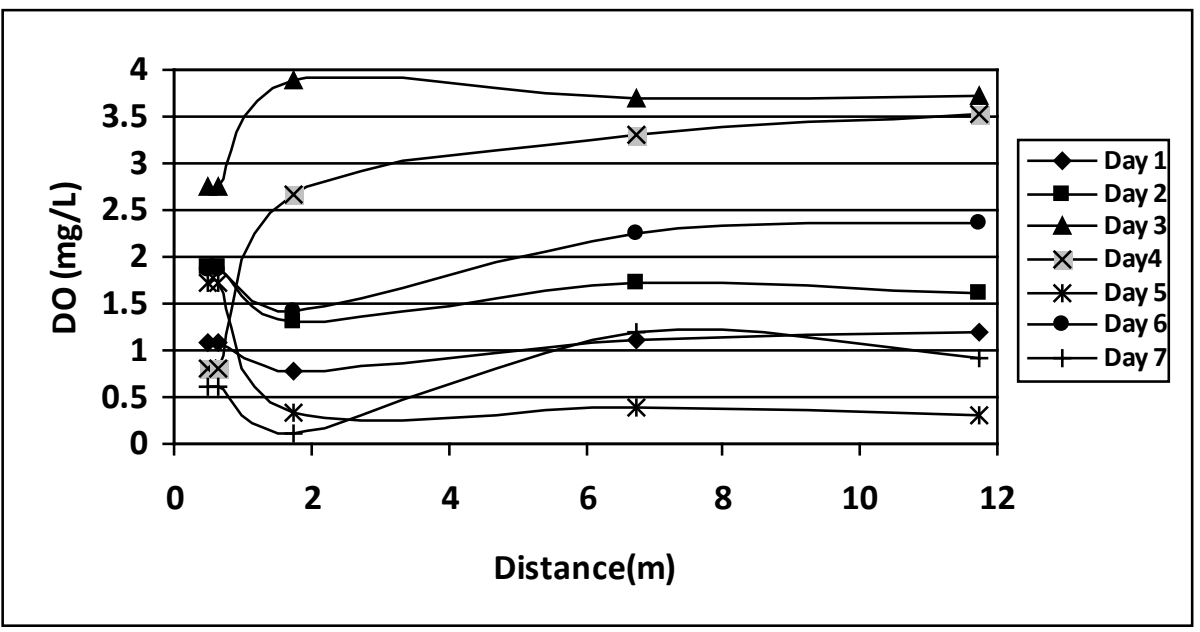

Figure (4) DO range through different samples locations

In general, the curves show a jump decreasing in DO concentration after media then increasing at the channel center and slightly decreasing at the end of channel.

Only for days $3 \& 4$ the value of DO showed jump increasing after media due to bacteria movement towards the media to decomposition the organic matter in the media and existing of algae after media which produce $\mathrm{O}_{2}$, then after day 4 bacteria increase after media due to increasing of $\mathrm{O}_{2}$ which led to activate bacteria and decreasing of DO. The decreasing of DO value after media indicated consumption of DO in decomposition processes by microorganisms.

Using of rice husk media increase DO by percent up to $40.58 \%$ while self purification process increase DO by 32.09\% through the length of the pilot, which is $10 \mathrm{~m}$ after media, which means decreasing of required length for self purification by $14 \mathrm{~m}$.

Figure (5) show the chemical oxygen demand (COD) concentration through the pilot length. In general, the curves show sudden decreasing in COD concentration after media then still constant till the center pilot channel and 
then increased with very small ratios at the end of the pilot for days $2 \& 7$ but decreased at the end of the pilot for day 5 only.

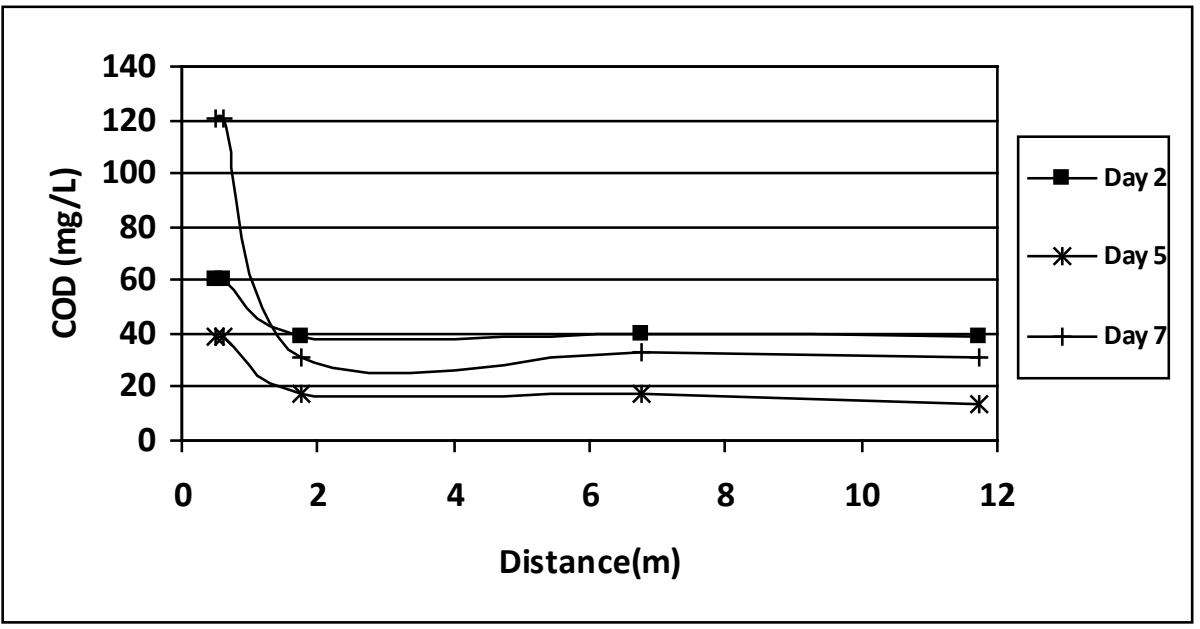

Figure (5) COD range through different samples locations

Using media of rice husk through polluted water in channel decreases COD concentration by percent up to $74.29 \%$ while self purification decreases the percent by $23.29 \%$ through the pilot length of $10 \mathrm{~m}$ which decrease the length required for self purification by $31.9 \mathrm{~m}$.

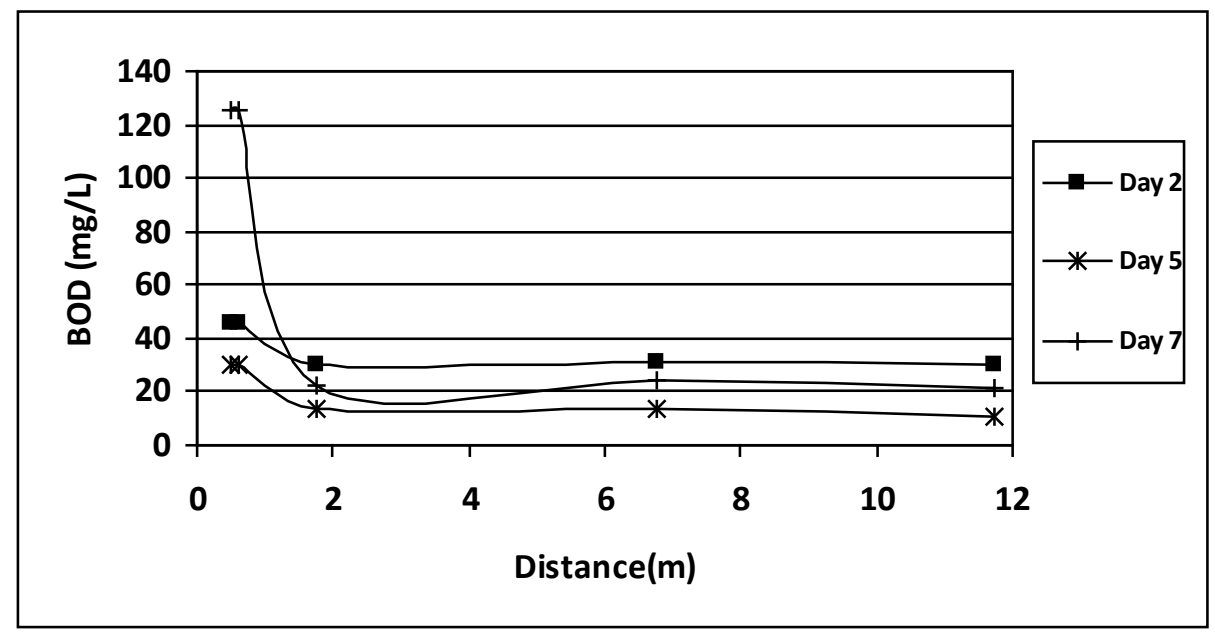

Figure (6) BOD range through different samples locations 
Figure (6) represent the chemical oxygen demand (BOD) concentration through the pilot length. In general, the curves show sudden decreasing in BOD concentration after media and stay constant till the center of the pilot channel and then vary with small ratios at the end of the channel.

The curve shows that the media decrease BOD concentration by percent up to $82.4 \%$ while self purification decrease the concentration by percent up to $22.96 \%$ which decrease the required length for self purification by $35.89 \mathrm{~m}$.

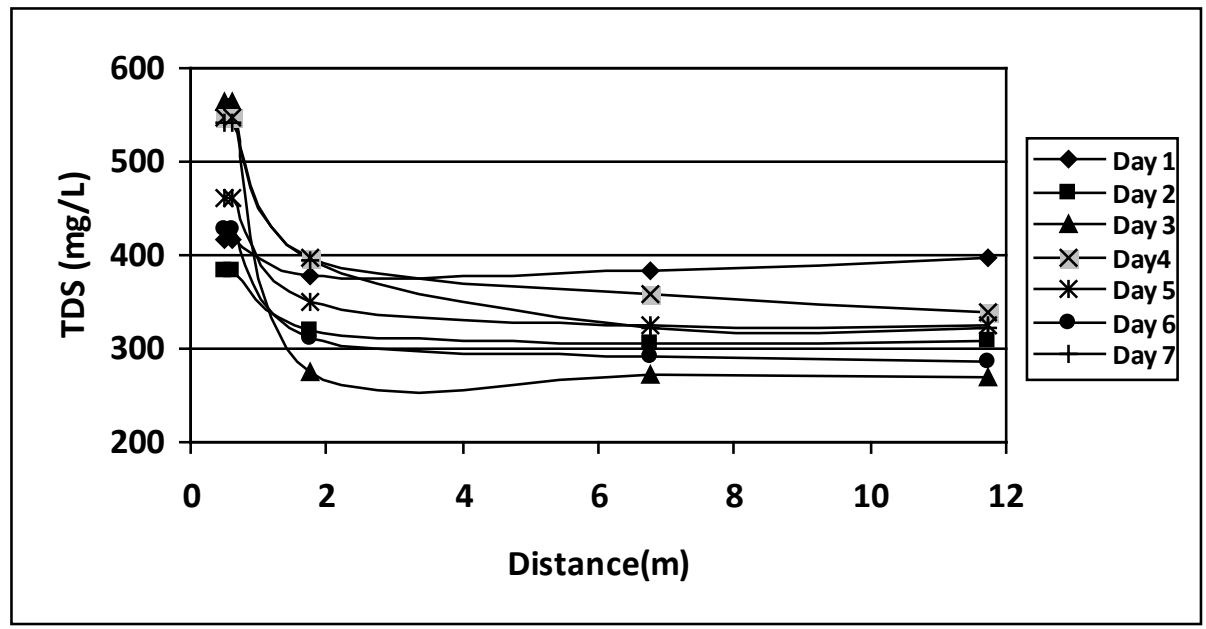

Figure (7) TDS range through different samples locations

Figure (7) represent the total dissolved solids (TDS) distribution through the length of the pilot channel. The curves show sudden decreasing of TDS concentration after media and then slightly decreasing along the pilot length till the end of pilot channel.

Using of rice husk as a biodegradable media decrease the concentration of TDS by percent up to $51.5 \%$ while decreasing of self purification process is up to $18.02 \%$ through length of $11 \mathrm{~m}$ which decrease the required length for self purification by $28.58 \mathrm{~m}$.

Figure (8) illustrate the change in turbidity through the pilot channel length. Turbidity had show sudden decreasing after media in very high values, gradually decreasing till the center of the channel. For day 1 and 5 the value of turbidity increased at the end of the channel due to increasing percent of algae in the channel. 


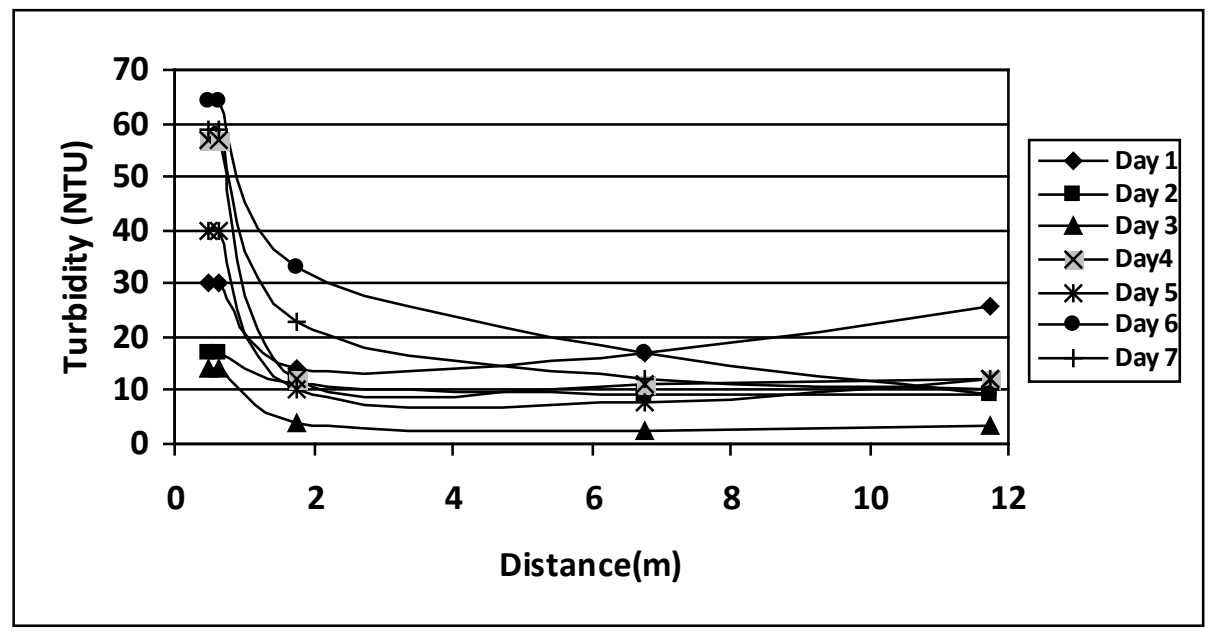

Figure (8) Turbidity range through different samples locations

The studied media of rice husk decrease turbidity by percent up to $78.95 \%$ while the percent of self purification is $56.52 \%$ which decrease the length required for self purification by $13.97 \mathrm{~m}$.

\section{CONCLUSION}

The study concluded the following points:

- Using a packing media of rice husk increase the amount of DO by $40.58 \%$ while the increasing due to self purification is $32.09 \%$ which reduce the required distance for self purification by $14 \mathrm{~m}$.

- The packing media reduce the concentration of COD and BOD in stream polluted water by $74.29 \%$ \& $82.4 \%$ comparing by self purification which is $23.29 \%$ \& $22.96 \%$ which reduce the required length for self purification by $31.9 \mathrm{~m} \& 35.89 \mathrm{~m}$.

- Rice husk decrease the amount of TDS and turbidity in the polluted water of the pilot channel in relatively high percentage up to $51.5 \%$ \& $78.95 \%$ compared with self purification process through the pilot length which decrease the percents by $18.02 \%$ \& $56.52 \%$ respectively, that means the media reduce the 
distance required for self purification to be $28.58 \mathrm{~m}$ for TDS and $13.97 \mathrm{~m}$ for turbidity.

- In general, rice husk, which is an agriculture waste, can be used as bioreactor packing media to improve wastewater characteristics in water stream bodies which help to accelerate self purification process through less distance.

\section{REFERENCES}

1. Voznaya, N. F., “Chemistry of Water and Microbiology”, Mir Publishers Moscow, (1981).

2. Belmont, M. A., Cantellano, E., Thompson, S., Metcalfe, C.D., "Treatment of domestic wastewater in a pilot-scale natural treatment system in central Mexico", Ecological Engineering Journal (ECOL ENG), vol. 23, no. 4, pp. 299-311, (2004).

3. El Sergany, F. A. GH., "Wastewater Treatment by Sugar Cane Waste Stalks”, Ain Shams Journal of Civil Engineering (ASJCE), Vol. No. 1, ISSN: 1687-8590, Egypt, (September 2009).

4. El Nadi, M. H., " USE OF ALMOND SHELLS FOR WASTEWATER TREATEMENT", Ain Shams Univ., Institute for Environmental Studies and Research, Journal of Environmental Science, vol. 15, No. 2, Egypt, (March 2009). 